\title{
Género gramatical de COVID-xenismos
}

\section{Grammatical Gender of COVID-Xenisms}

\author{
Iva Svoвodová [9255@mail.muni.cz] \\ Masarykova univerzita, República Checa
}

\begin{abstract}
RESUMO
O presente texto ocupa-se do tema de neologismos que surgiram como palavras novas ou atualizaram o seu escopo semântico durante a pandemia da COVID-19. O alvo da pesquisa foi monitorar o conhecimento geral e a integração morfológica das expressões burnout, COVID-19, covid-longa, covid-drive, fake-news, hoax, lockdown, remdesivir/rendesivir, webinar e zoonose na língua portuguesa. O estudo foi realizado com base num inquérito distribuído em março e abril de 2021 e baseado em seis fatores sociolinguísticos: nacionalidade, residência, sexo, formação, idade e média preferidos. Destes fatores mostraram-se como os mais relevantes o diatópico e o de formação, sobretudo, no que diz respeito ao grau de (des)conhecimento e à oscilação do género gramatical, que habitualmente ocorre, no uso real, apesar da sua dicionarização. Com base nos dados recolhidos, propomos calcular o coeficiente e o grau de oscilação genérica, que deveriam contribuir para a dicionarização mais completa e efetiva das palavras de género gramatical instável.
\end{abstract}

\section{PALAVRAS-Chave}

COVID-19; neologismos; estrangeirismos; género gramatical; coeficiente de oscilação gramatical.

\section{Abstract}

This text deals with the theme of neologisms that emerged as new words or updated their semantic scope during the COVID-19 pandemic. In particular, the expressions burnout, COVID, long-COVID, COVID-drive, fake-news, hoax, lockdown, remdesivir (rendesivir), webinar and zoonosis were analysed. The aim of the research was to monitor two factors associated with them: their general knowledge by native speakers of different Portuguese-speaking nationalities and their morphological integration in the Portuguese language. The study was based on a survey distributed in March and April 2021 and on six sociolinguistic factors: nationality, residence, sex, education, age, and preferred media. Of these factors, the most relevant were the diatopic and the educational ones with regard to the degree of (un) knowledge and the oscillation of the grammatical gender of the neologisms in question, which usually occurs, in real use, despite their integration in the dictionaries. Based on the collected data, we propose to calculate the generic oscillation coefficient and degree that should contribute to the most complete and effective lexicographic treatment of the generically unstable words.

\section{KEYWORDS}

COVID-19; neologism; borrowed words; grammatical gender; coefficient of the gender oscillation. 


\section{Introdução}

O tema principal tratado no presente artigo são os neologismos que têm sido importados para a língua portuguesa como estrangeirismos (ou empréstimos próprios segundo a tipologia de Haugen 1950) de origem inglesa durante a pandemia da COVID-19. Os estrangeirismos de origem inglesa não só pertencem aos mais frequentemente registados na língua portuguesa durante a altura de combate ao vírus, como também provam a tendência mais geral da adoção do vocabulário inglês, aliás predeterminada pelas "numerosas mudanças económicas e sociais" e pela "aceitação dos modelos culturais estrangeiros, sobretudo americanos e ingleses" pela sociedade portuguesa e brasileira de acordo com, p. ex., Jabłonka (2016: 299). Focalizaremos, na nossa pesquisa, naquelas lexias inglesas (i.e. tanto palavras como expressões fixas) que foram parcialmente aportuguesadas, apesar de a sua grafia se manter na sua forma original. Este tipo de palavras costuma ser designado, na linguística, pelo termo xenismo (cf. Jabłonka 2016). Alguns deles adotaram a pronúncia portuguesa, alguns servem de base para a formação de palavras cognatas de acordo com os princípios morfológicos ou lexicológicos da língua portuguesa, mas a todos foi atribuída a categoria gramatical de género.

A nossa atenção será focalizada em dois problemas associados ao seu uso: o conhecimento geral e a oscilação do género gramatical no uso real por parte dos falantes das diferentes variedades da língua portuguesa.

Em primeiro lugar, observaremos o grau de (des)conhecimento destes neologismos e a sua relação com o nível de dicionarização, partindo do facto, geralmente aceite, de que os neologismos são palavras que nem sempre se tornam parte do vocabulário comummente utilizado e dos dicionários. E isso apesar de uma das suas metas principais ser refletir a constante evolução da língua e os avanços tecnológicos e científicos da sociedade.

Em segundo lugar, ocupar-nos-emos do problema da oscilação do género gramatical destes vocábulos. Este é-lhes atribuído, muitas vezes, independentemente da sua dicionarização ou tendência de uso a esta precedente (p. ex. nos meios-de-comunicação), sendo sujeito a diferentes processos cognitivos.

A nossa análise, na maior parte quantitativa, assenta num questionário distribuído entre 342 informantes (329 falantes nativos de Portugal, do Brasil, de Cabo-Verde, de Angola, de São Tomé e de Moçambique e 15 falantes de PLE Português- Língua Estrangeira, que participaram do inquérito por curiosidade, mas que também nos trazem dados preciosos e úteis, sobretudo, para a área da didática da língua portuguesa). Com base nos dados recolhidos, pretende-se apontar para uma desproporção considerável entre a dicionarização dos vocábulos analisados e o seu conhecimento geral, e estabelecer o coeficiente e o grau da sua oscilação genérica. 


\section{Enquadramento teórico}

\subsection{Neologismos}

Na nossa pesquisa, partimos da conceção do neologismo enquanto uma palavra nova que surge num determinado período como reação à nova realidade extralinguística, refletindo a evolução dinâmica da sociedade. Os neologismos que têm sido importados para o português durante a pandemia da COVID 19 (2020-2021) são, sobretudo, de origem inglesa e pertencem a diferentes esferas da vida social e pública: saúde, ensino, educação, meios de comunicação, economia, alimentação, etc. Ao mesmo tempo, incluímos neles alguns vocábulos já conhecidos e usados antes da pandemia, mas cujo escopo semântico se tem atualizado, adaptando-se à situação vivenciada. Portanto, o principal critério da criação do repertório analisado é a sua vinculação temporal a um determinado período.

Para além deste fator diacrónico, há autores como Ferraz (2010: 67-68) que consideram ainda outros três critérios: lexicográfico, psicológico e de instabilidade sistemática.

Quanto ao fator lexicográfico, o autor afirma que uma palavra importada de outras línguas e não registada nos dicionários, pode já ser considerada neológica na língua-alvo. Na nossa pesquisa, no entanto, focalizaremos no problema da não dicionarização de estrangeirismos que já se tenham tornado parte do vocabulário usado no dia-a-dia. Para tal, recorremos aos dicionários de tipo on-line, que são, obviamente, mais flexíveis quanto à inclusão de novas palavras. Os resultados da nossa pesquisa vão mostrar, por exemplo, que há dicionários que ainda não registaram a expressão fake-news, apesar de se tratar de palavra-chave do início do século XXI com a função denominativa estável. Por outro lado, a palavra COVID-drive, que surgiu relativamente há pouco tempo, já se encontra integrada em alguns dicionários, por exemplo, no PRIBERAM. Em relação a este problema importa ainda assinalar que há dicionários (p. ex. Caldas Aulete e, em grande parte, também, MICHAELIS- Dicionário Brasileiro da Língua Portuguesa) que evitam, por princípio, a inclusão dos estrangeirismos ou que reagem mais lentamente à evolução da sociedade, quando, ao mesmo tempo, [...] se autodefinem como a ferramenta mais útil no que diz respeito à reação rápida ao desenvolvimento dinâmico da língua." (t.n.) (Polická 2006: 141). Sablayrolles (2006: 142-143) chega ao ponto de denominar as palavras não dicionarizadas como palavras SDF (sans domicile fixe - palavras sem-abrigo). Um exemplo destes vocábulos indigentes, ignorados pela lexicografia em geral, são os neologismos da cultura hip-hop, p. ex. hardcore (cf. Polická 2018: 207). Para além disso, Correia e Almeida (2012: 22-23) advertem de que não só todos os neologismos não entram nos dicionários, mas alguns, até, depois de entrarem, desaparecem por caírem em desuso.

No que se refere ao fator psicológico, Ferraz aponta para o facto de que uma palavra pode ser considerada neologismo se os falantes a avaliam como uma palavra nova. Apesar de se tratar de uma questão bem polémica, baseada, muitas vezes, em conclusões empíricas, ela pode ser monitorada cientificamente através da observação do grau de (des)conhecimento. E, como já antecipámos no início, é precisamente este um dos objetivos da nossa pesquisa: tentaremos estabelecer uma relação entre o fator psicológico e o lexicográfico e, assim, apontar para uma desproporção

1

t.n. (tradução nossa) 
entre o grau de conhecimento e o nível de dicionarização. Por exemplo, a palavra fake-news, que era conhecida por todos os nossos informantes, não aparece registada no PRIBERAM, enquanto a palavra covid-drive, desconhecida por $40 \%$ dos nossos informantes, já faz parte da mesma fonte. E a lista continua.

E, quanto à instabilidade morfológica, esta pode ser observada em todo o espectro das categorias gramaticais. Mas o que mais chamou a nossa atenção tem sido a sua oscilação genérica. Assim, o objetivo da nossa investigação será estabelecer, no corpus por nós delimitado, cinco graus de oscilação a serem deduzidos do coeficiente calculado com base na fórmula explicada no enquadramento teórico. Relembremos que, para além da aludida instabilidade morfológica e lexicográfica, os neologismos também podem evidenciar instabilidade gráfica: online versus on-line, e fonética |strési| versus $\left|\int t^{\prime}{ }^{\prime} \varepsilon s i\right|$ versus $\left|\mathbf{i} \int t^{\prime}{ }^{\prime} \varepsilon s i\right|$ (da palavra stresse).

Quanto à tipologia, a classificação mais relevante e mais panorâmica de neologismos foi elaborada por Cabré Castellví (p. ex. 2006) e por Sablayrolles (p. ex. 2019).

Cabré Castellví (2006: 231-235) divide os neologismos nos seguintes grupos:

- Neologismos formais - são palavras novas criadas através dos processos de sufixação, prefixação, parassíntese, composição e truncamento.

- Neologismos por variação ortográfica - são palavras novas cuja ortografia pode variar (p. ex. online, on-line).

- Neologismos sintáticos - são palavras que implicam uma mudança de categoria gramatical na base lexical (p. ex. em castelhano: el amo de casa - la ama de casa).

- Neologismos semânticos - palavras que consistem na modificação semântica da base lexical e que incluem, também, os nomes próprios ou marcas registadas (p. ex. tupperware).

- Empréstimos - unidades importadas de uma outra língua (p. ex. ghetto, sushi).

- Outros - a autora inclui, nesta categoria, as palavras novas que ocorrem como palavras simples, palavras diatopicamente limitadas (dialetais), o calão e a gíria, os cultismos e outros casos de etiquetagem não unânime (p. ex. fitipaldi, yuyu).

Já Sablayrolles (2009: 127) sugere a classificação baseada na terminologia emprestada de Tornier e Tornier (2009): matrizes internas e externas. Entre as matrizes internas inclui os neologismos puramente morfológicos, morfossemânticos, sintático-semânticos e fraseológicos e, entre as matrizes externas, as palavras emprestadas de outras línguas. Resumimos, em breve, as suas descrições de seguida:

Matrizes internas:

- Neologismos puramente morfológicos - são palavras truncadas, abreviadas, siglas e acrónimos (p. ex. $L M D$ ).

- Neologismos morfossemânticos - são palavras criadas por meio dos processos de afixação (p. ex. détatouer), composição (p. ex. ptochophobie) ou de imitação (p. ex. wishhhhh, dzoing).

- Neologismos sintático-semânticos - são neologismos que surgem com base na mudança da função sintática (p. ex. la gagne) ou semântica (p. ex. thermique).

- Neologismos fraseológicos - são neologismos superiores a uma unidade lexical (p. ex. faire du huit mégabits ou faire marcher la planche à promesses). 


\section{Matrizes externas:}

- Palavras emprestadas de outras línguas (p. ex. quantified-self).

No contexto da lexicologia portuguesa parte-se, em grande parte, das classificações citadas. Em geral, existe um consenso quanto à divisão dos neologismos em completos (palavras completamente novas) e incompletos (palavras existentes na língua, mas que adquirem um outro significado), autóctones/vernaculares (que correspondem às matrizes internas, i.e., surgem dentro da própria língua através dos seus próprios processos) ou não autóctones/importadas (que correspondem às matrizes externas e provêm de outros sistemas linguísticos) (cf. Boulanger 1978; Biderman 2001). Entre os neologismos não autóctones, habitualmente, contam-se os estrangeirismos e os empréstimos. Os estrangeirismos (ou xenismos) são palavras procedentes de outras línguas, incorporadas no vocabulário de uma língua - alvo, mas mantendo a sua grafia e, em diferentes medidas, também a sua pronúncia. Os empréstimos são palavras novas que foram incorporadas com modificações gráficas, assumindo a escrita da língua-alvo.

No entanto, os autores não são, de todo, unânimes no que diz respeito à delimitação dos seus variáveis subtipos. Encontrámos, em diferentes fontes, os seguintes:

- Neologismos fonológicos - são palavras cujo significante é completamente novo, e que se opõem aos neologismos onomatopeicos (Alves 1994).

- Neologismos onomatopeicos - são palavras que refletem a imitação do som do objeto designado (Alves 1994).

- Neologismos lexicais ou formais - são palavras novas que denominam uma nova realidade (p. ex. COVID-19) e podem envolver, também, os neologismos técnicos e científicos (como se refere de seguida).

- Neologismos técnicos e científicos - são palavras que designam uma nova invenção ou descoberta (p. ex. covid, zoonose, task-force) (cf. Biderman 2001).

- Neologismos semânticos - são palavras que já existem na língua, mas que adquirem um outro significado (cf. Carvalho 2002). Por exemplo, em inglês, a palavra burn-out, cujo significado primário era queimar, passou a adquirir a forma burnout e a designar o tipo de esgotamento físico, mental associado à atividade profissional. Em português, a palavra tributo, que já existia como imposto, passou a designar homenagem.

- Neologismos sintáticos - são palavras novas criadas com base nos processos de derivação, composição ou truncamento (Alves 1994; Rio-Torto 2020), p. ex.: antimáscara, bolsotrumpista, SARS, respetivamente. Segundo vários autores (p. ex. Eckert 2019), podem envolver construções fraseológicas ou idiomáticas compostas de mais palavras que remetem para um terceiro significado (p. ex.: dar um bafão, ser show de bola) (Eckert 2019: 7). ${ }^{2}$

- Neologismos literários - são palavras criadas por um escritor. Por exemplo, as expressões brincriações, abensonhadas, ladainhando, bichanar, lençolar ${ }^{3}$ são consideradas neologismos da autoria de Mia Couto (cf. Eckert 2019).

2 Eckert, no entanto, adverte para o facto de não ser habitual a neologia de expressões idiomáticas através de palavras importadas de outra línguas.

3 https://www.normaculta.com.br/neologismo/ 
- Neologismos populares - envolvem palavras usadas, primeiro, por uma comunidade específica, mas que passaram a fazer parte do vocabulário comum (cf. Eckert 2019) (p. ex. viado, bicha, baitola, sapatão, sapatona, caminhoeira, gobi, trava, traveco). (Carvalho, 2021: 131 e 136).

Na nossa pesquisa focalizamos nos neologismos científicos, técnicos e semânticos que estão, de momento, a ser usados nas suas formas originais, em concreto, burnout, COVID, COVID-longa, COVID-drive, fake-news, hooax, lockdown, remdesivir (remdesivir), webinar e zoonose. Trata-se de anglicismos que, ao mesmo tempo, passaram por um parcial aportuguesamento (não formal, mas gramatical) uma vez que adotaram o género gramatical (a zoonose) e, em alguns casos, também o plural (os hoaxes). Alguns deles já participam dos processos da formação a partir da base que também se mantém na forma original (covídico, covid-divórcio, etc.).

\subsection{Género gramatical dos neologismos}

A atribuição do género gramatical é submetida a diferentes processos e foi alvo de estudo de, por exemplo, Gouveia (2003: 415), que, na sua pesquisa, identificou os seguintes aspetos decisivos para a adoção desta categoria gramatical:

a) A natureza animada do empréstimo: Os estrangeirismos animados, que possuem o género ontológico, claramente, adotarão, na língua-alvo, o género natural conforme o sexo implícito e inerente. Assim, a adoção do género pelas palavras como o barman ou o cameraman vê-se predeterminada pelo radical man. Ao mesmo tempo, Gouveia (2003: 414) adverte de que mesmo nestes referentes sexuados, a atribuição de género é definitiva, não mudando a concordância nominal nas construções tipo: Ela é snob. Ela é designer.

No caso dos nomes inanimados, Gouveia (2003: 413-415) explicita que aos fatores decisivos pertencem:

b) O género gramatical da palavra na sua língua de origem: os neologismos ou empréstimos, dotados do género gramatical na língua de origem, podem, na língua-alvo, manter o mesmo género (p. ex.: a pizza, a langerie, o menu, o ballet).

c) O género mais comum na língua de origem: os anglicismos adotam, mais frequentemente, o género mais comum que é o masculino (p.ex.: o slogan, o bar, o conhaque).

d) A terminação da língua de origem: à palavra adotada pode ser atribuído o género segundo a terminação (p. ex.: a maionese - analogamente à catequese, o biberon - analogamente ao bombom).

e) Equivalentes na língua de adoção: a palavra adota o género do seu equivalente traduzido para a língua-alvo. Assim, a T-shirt adotou o género feminino do nome camisa, a home-page, dos nomes casa e página, a net, do nome rede, a home-page do nome a página, o after-shave do nome bálsamo, o pijama, do nome fato de dormir, etc.

f) Fator diatópico: a autora adverte do facto de o género poder ser atribuído de modos diferentes em Português Europeu (doravante PE) e em Português do Brasil (doravante PB), (p. ex: o san- 
duíche (PB) versus a sanduíche (PE), a gangue (PB) versus o gangue (PE), as mídia (PB) versus os mídia $(\mathrm{PE})$, o soçaite. $(\mathrm{PB})$ versus a high society $(\mathrm{PE}))$.

No corpus por nós estudado, portanto, pressupomos que será usado ou o género comum masculino ou, então, o género do equivalente traduzido. Ao mesmo tempo, pressupomos haver uma diferença diatópica. Não se considera como decisiva a terminação da palavra, porque todas terminam em consoante, com a exceção de COVID-longa, com o género explicitamente indicado.

\subsection{Uso metaftonímico}

Das tendências da formação de género supracitadas merece a especial atenção o ponto e) em que falamos sobre as equivalências terminológicas entre duas línguas. Teixeira (2020), no seu artigo sobre as metáforas da vida covid(t)idiana, procura ressaltar a distância entre a expressão metafórica e não metafórica de várias palavras usadas nos meios-de-comunicação durante a pandemia da COVID 19. Assim, no contexto de combate ao vírus, deteta diferentes graus de proximidade entre o significado original, prototípico, e o significado metafórico da palavra guerra na linguagem jornalística, dando como exemplo Portugal em guerra com o vírus assassino ou Marcelo declara guer$r a$ (Teixeira 2021: 16). O autor, após sugerir um esquema de aproximação semântica de dois polos de um significado, concluiu que estes podem levar à oscilação do género gramatical. No caso de COVID, por exemplo, ilustra que o uso instável do género se vê associado a duas componentes do mesmo significado: a primária (original) e a metafórica (figurativa): a COVID significa, originalmente, a doença do vírus corona (CoronaVIrusDesease), e, o COVID, o próprio vírus, que é o seu significado metafórico que o autor denomina metaftonímico:

O nome técnico do vírus é SARS-CoV-2, assim mesmo, com maiúsculas, uma minúscula e um número. Mas raramente ele é usado para referir o vírus, preferindo-se coronovírus ou COVID-19, embora, em rigor, não sejam referências equivalentes. Mas como a linguagem cotidiana não é rigorosa, mas metaftonímica, qualquer destas referências é usada, muitas vezes, como se todos fossem termos sinónimos. E a prova disso é, por exemplo, aparecer escrito, como tantas vezes aparece na imprensa e no uso diário, "o COVID” em vez de "a COVID”, já que COVID equivale a "doença do vírus corona” (COronaVIrusDesease). Usar o masculino indicia, naturalmente, referência (metonímica) ao vírus. (Teixeira 2021: 43).

O autor dá-nos uma resposta prévia às nossas dúvidas acerca da oscilação do género gramatical não apenas da palavra COVID como também, de, praticamente, todas as expressões que fazem parte do nosso corpus, que podem ser associadas a diferentes equivalências lexicais e, remetendo para a mesma realidade, são usadas como sinónimos metafóricos ou metaftonímicos. 


\section{Metodologia}

Sendo definidas as propriedades do corpus que pretendemos analisar, isto é, palavras na forma original que adotaram o género gramatical e que pertencem ao campo lexical da pandemia da COVID-19, chegamos a identificar, na lista de Léxico COVID-194, criada pelo Ciberdúvidas da Língua Portuguesa (doravante como Ciberdúvidas), 13 lexias inglesas: burnout, lay-off, COVID, coronabonds, COVID-drive, fake-news, hooax, task force, lock down, remdesivir, take-away, webinar, zoonose e uma palavra composta de um radical inglês e um radical português (COVID-lon$g a)$. Excluímos da lista, praticamente, as palavras formadas por truncamento. Devido aos limites dados pelas normas de publicação, no entanto, no presente artigo, limitar-nos-emos a analisar as seguintes palavras: burnout, COVID, COVID-drive, fake-news, hooax, lock down, rem(n)desivir, webinar e zoonose. Quanto às restantes, isto é, lay-off, coronabonds, task force e take-away, estas serão tratadas numa outra publicação.

O questionário, criado no programa survio.com, ${ }^{5}$ foi distribuído entre 342 falantes de nacionalidade portuguesa, brasileira, cabo-verdiana, mas também angolana, moçambicana e são-tomense. Não conseguimos obter respostas de todos os países e, mesmo na categoria das últimas três nacionalidades, o número de respondentes foi mínimo. Ao mesmo tempo, 15 informantes foram de origem outra que lusófona. Estes participaram do inquérito por curiosidade e serão tratados como categoria "outros".

O inquérito foi dividido em duas partes: a sociolinguística e a linguística.

$\mathrm{Na}$ primeira parte incluímos os seguintes fatores sociolinguísticos: a nacionalidade, o país de residência, a formação (básica, secundária, universitária), idade (dividida em cinco faixas etárias segundo os graus de formação, idade de produtividade laboral, e reforma), o sexo (masculino, feminino, eventualmente, outro) e os meios-de-comunicação preferidos (televisão, rádio, jornais).

A segunda parte, isto é, a linguística, contém 13 questões em que ao respondente é pedido para selecionar uma das quatro respostas que contêm o nome no género masculino, feminino, em ambos os géneros ou, então, no caso de os respondentes desconhecerem a palavra, podem selecionar a resposta "não conheço a expressão", tendo ainda a possibilidade de intercalar, em cada uma das questões, um comentário próprio.

$\mathrm{Na}$ análise dos dados, consideramos como o género gramatical por excelência aquele que se encontra dicionarizado. Observaremos a integração dos neologismos analisados nos seguintes dicionários online:

- PRIBERAM (disponível em: https://dicionario.PRIBERAM.org/)

Extensão: 133 mil entradas lexicais.

- Calda Aulete (disponível em: http://aulete.com.br/)

Extensão: mais de 800 mil entradas lexicais (verbetes).

$4 \mathrm{https} / /$ ciberduvidas.iscte-iul.pt/lexico-covid-19/pagina/1

5 Página de acesso: https://www.survio.com/survey/d/D8Q4A4A2J3K4T2N6S 
- Grande Dicionário Houaiss (doravante HOUAISS) (disponível em: http://houaiss.uol.com.br/) Extensão: 228500 verbetes, 376500 aceções, 415500 sinônimos, 26400 antônimos e 57000 palavras arcaicas.

- Dicionário Brasileiro da Língua Portuguesa (doravante MICHAELIS) - Michaelis (disponível em: https://michaelis.uol.com.br/)

Extensão: 167 mil verbetes, 350 mil aceções, 27 mil expressões e 47 mil exemplos e abonações.

- Dicionário Online de Português (doravante DICIO) (disponível em: https://www.dicio.com.br/) Extensão: 400 mil palavras.

Este será comparado com o uso real. Com base nos dados obtidos será calculada a medida de oscilação, que propomos denominar como "coeficiente de oscilação genérica" (c.o.g.), e que corresponderá à diferença percentual entre os respondentes que marcaram o género masculino e os que marcaram o género feminino. Ao mesmo tempo, estabelecemos cinco graus de oscilação genérica (g.o.g.) de acordo com a Tabela 1:

\begin{tabular}{|c|c|}
\hline coeficiente c.o.g. & grau g.o.g. \\
\hline $0-20$ & 5 \\
\hline $21-40$ & 4 \\
\hline $41-60$ & 3 \\
\hline $61-80$ & 2 \\
\hline $81-100$ & 1 \\
\hline
\end{tabular}

Tabela 1: Coeficiente e grau de oscilação genérica

Deduza-se, portanto, que quanto menor é o coeficiente, tanto maior é o grau de oscilação. Por exemplo, no caso do neologismo COVID-19, 43\% dos informantes marcaram o género masculino e, 42\%, o feminino. Então, neste caso, obtivemos o coeficiente 1 (e.g. 43\%-42\%) que corresponde ao máximo, o quinto, grau de oscilação genérica. $\mathrm{O}$ método proposto, baseado na calculação deste coeficiente, poderá contribuir para o processo de dicionarização mais efetivo no caso das palavras com o género gramatical instável.

Focalizaremos a nossa atenção nos resultados que dizem respeito aos falantes da língua portuguesa, sobretudo Brasil, Portugal e Cabo-Verde, i.e. categorias em que obtivemos os números mais altos. As outras nacionalidades, incluídas, igualmente, nos dados dos gráficos, podem servir como uma amostra, mas, por haver um número mínimo de respondentes que impedem qualquer tipo de generalização, não são comentados, tal como no caso das outras nacionalidades incluídas na categoria "OUT" (abreviação de "outros", eventualmente, equivalente de "fora" do espaço lusófono). Ao mesmo tempo, usar-se-ão as abreviaturas ANG (para Angola), BR (Brasil), CV (CaboVerde), MOÇ (Moçambique), PT (Portugal) e ST (São Tomé e Príncipe). 


\section{Resultados do questionário}

\subsection{Perfil dos respondentes}

Ao analisar os resultados relacionados com a primeira parte do inquérito, na qual incluímos os fatores sociolinguísticos básicos, isto é, a nacionalidade, o país de residência, a idade, o sexo, a formação e os meios de comunicação preferidos, obtivemos os seguintes perfis dos informantes.

Quanto à nacionalidade, conseguimos ter 268 respondentes de nacionalidade lusófona como mostra o Gráfico 1:

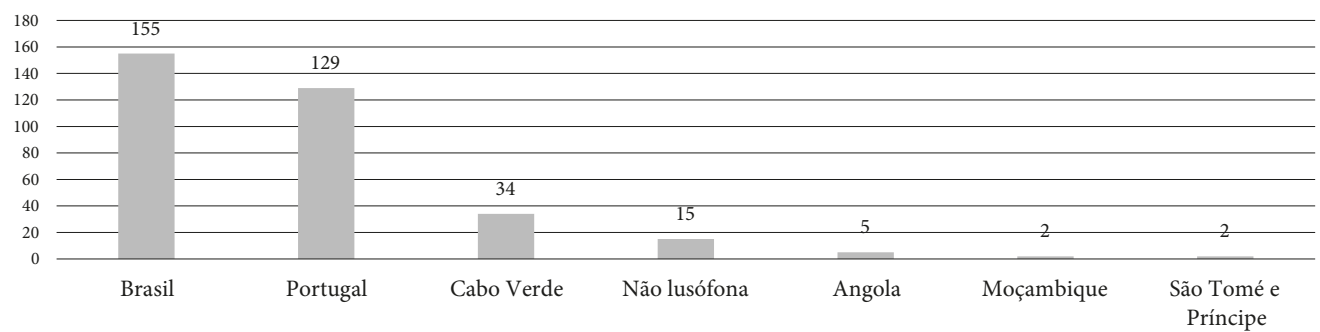

Gráfico 1: Nacionalidade dos respondentes lusófonos

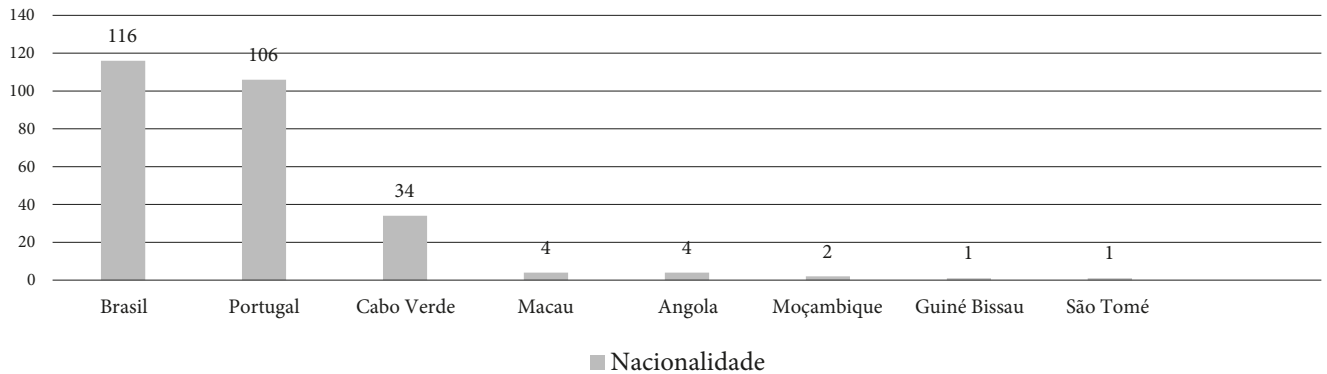

Gráfico 2: País de residência (dentro de CPLP) dos respondentes lusófonos

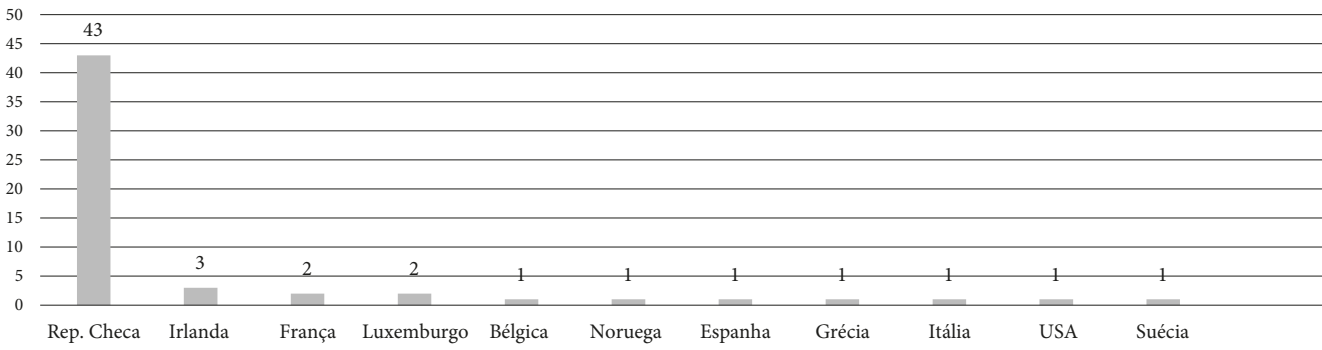

Gráfico 3: País de residência (fora de CPLP) dos respondentes lusófonos 
Importa explicar que o país de residência dos respondentes lusófonos nem sempre corresponde ao de origem. Os dados são, no entanto, semelhantes, existindo apenas uma leve diferença, a qual, no entanto, como veremos, acabará por se mostrar como irrelevante para a nossa pesquisa. Como o Gráfico 2 e o Gráfico 3 mostram, 268 dos respondentes vivem dentro do espaço de CPLP e, 57, fora.

Ao mesmo tempo, houve 15 respondentes de nacionalidade outra, que não a lusófona, espalhados por vários países, tanto dentro como fora do espaço CPLP (veja-se o Gráfico 4).

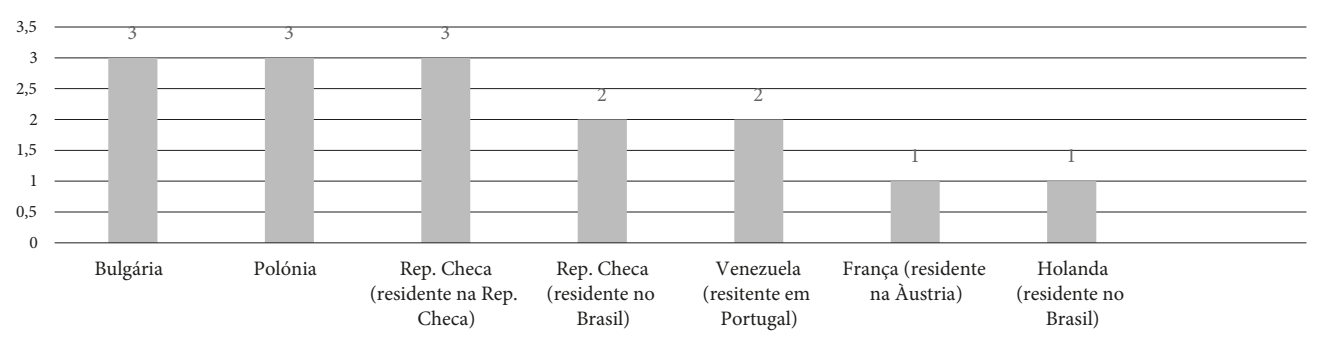

Gráfico 4: Nacionalidade dos respondentes não lusófonos

Quanto ao fator de formação, a maior parte dos respondentes indicaram terem formação universitária (299 respondentes). Ao mesmo tempo, houve 40 respondentes com formação secundária, e, 3, com formação básica, como podemos observar no Gráfico 5 .

Quanto à idade, a maior parte dos respondentes pertence à faixa etária de 26-50 anos, portanto, são pessoas que, obviamente, não só estão a par da situação pandémica (como as outras faixas), mas, ao mesmo tempo, estão, pressupostamente, em contacto permanente com o inglês e com os meios de comunicação. Uma parte significativa pertence ainda à faixa etária de 51-64 anos, e envolve pessoas na última década de produtividade laboral, portanto, supõe-se neles uma atitude mais passiva quanto ao uso dos estrangeirismos na linguagem corrente. As outras três faixas, no entanto, mostram-se mais periféricas (10-18, 19-26 e 64+) como se observa no Gráfico 6:

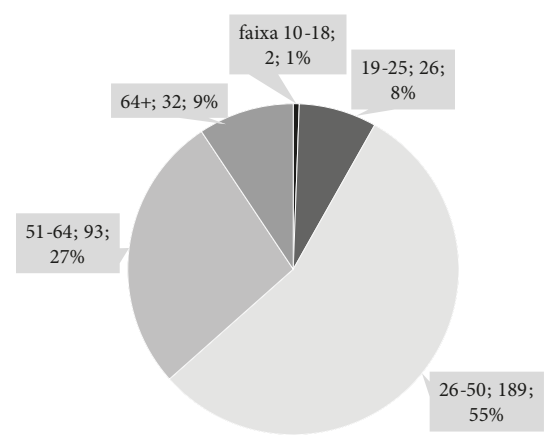

Gráfico 5: Idade dos respondentes

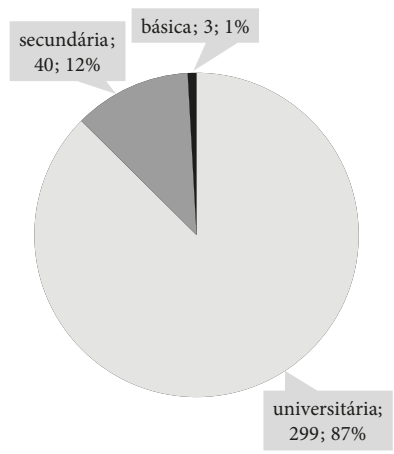

Gráfico 6: Formação: dos respondentes 
O fator dos meios de comunicação foi também incluído, uma vez que eles são os “[...] principais responsáveis por difundir os neologismos recém criados. [...]" (Alves 2002: 6) e fonte de penetração das novidades (Carvalho 1987: 62). Partimos, portanto, da hipótese de, também, a atribuição do género poder ser influenciada pelos tipos de meios de comunicação que os respondentes preferem seguir. Pressupomos que os textos escritos permitem a fixação visual e, portanto, mais explícita, enquanto nos recursos de produção oral, a cadência e o ritmo da fala rápida podem ser causa de uma perceção mais vaga das marcas do género, e.g., das vogais átonas finais. Como o Gráfico 7 demonstra, 124 respondentes preferem ver televisão, 22, ouvir rádio, 67 , ler jornais, e 129 informantes indicaram dar preferência a: internet em geral, blogs, sites, podcasts, redes e média sociais - jornais digitais, média não convencionais, Facebook, Twitter, Instagram, Whatsapp e outras redes sociais que permitem seguir ambos os tipos de linguagem: tanto falada como escrita.

O sexo, enquanto fator sociolinguístico básico, também foi incluído na primeira parte do questionário. Como se pode consultar no Gráfico 8, 233 dos respondentes foram mulheres, 107, homens, e 2 marcaram a resposta "outro", que incluímos nas opções por não marginalizar as pessoas que não se sentem enquadradas no género padrão.

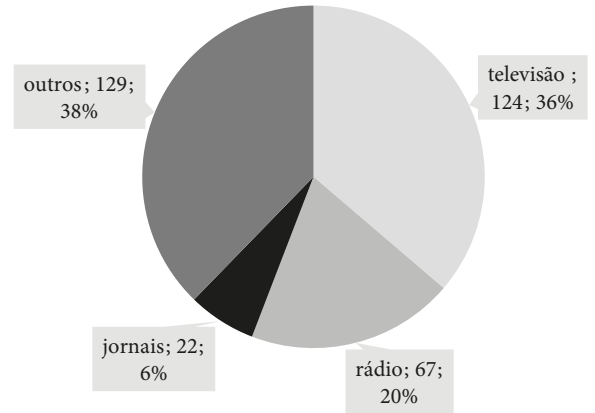

Gráfico 7: Meios de comunicação preferidos

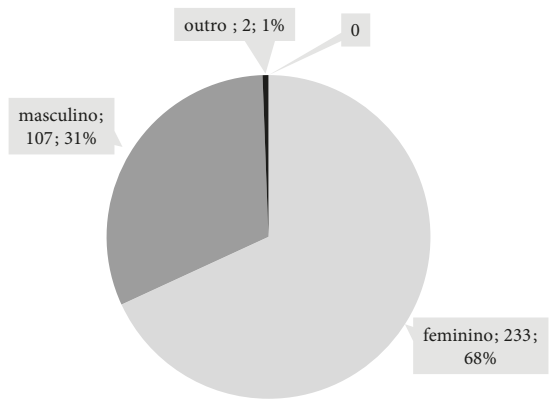

Gráfico 8: Sexo dos respondentes

\subsection{Resultados da análise quantitativa}

Todas as respostas obtidas parecem confirmar que a atribuição do género aos neologismos é um processo geralmente oscilante e decorre, praticamente, de uma forma proporcional em quase todo o espectro dos fatores sociolinguísticos. Os fatores de maior relevância foram a nacionalidade e a formação. A seguir, apresentamos os resultados relativos aos neologismos escolhidos. Em cada um deles limitar-nos-emos a inserir dois gráficos: um com os resultados gerais e um outro com os resultados conforme o fator de nacionalidade, sendo o fator de formação comentado sempre que necessário. 


\section{BURNOUT}

A palavra burnout é uma palavra inglesa, que foi integrada como nome de género masculino nos dicionários PRIBERAM e DICIO e que é registada, também, no HOUAISS (com base no conteúdo da Wikipedia) mas sem qualquer descrição morfológica. É um termo usado na área da medicina e o seu significado é definido como um "tipo de esgotamento físico e mental associado à actividade profissional"6 ou como "distúrbio psíquico ocasionado pelo excesso de trabalho, sendo capaz de levar alguém à exaustão extrema, estresse generalizado e esgotamento físico; comumente conhecido como Esgotamento Profissional ou Síndrome do Esgotamento Profissional"7 . Pode ser substituído pelo próprio nome esgotamento (segundo DICIO) ou pela expressão "síndrome de burnout" (segundo PRIBERAM, que também refere a sua transcrição fonética |bârnáute|). No contexto da pandemia, segundo o Ciberdúvidas, passou a significar o estado de exaustão dos profissionais de saúde que se encontram na "linha da frente" no combate à COVID-19 e "uma das preocupações maiores, além do número assustadoramente crescente de médicos, enfermeiros e demais pessoal hospitalar contagiados - e mortos - por esta pandemia. $[\ldots]^{8}$

Quanto aos resultados gerais, como o Gráfico 9 demonstra, 24\% dos falantes não conhecem a palavra. Trata-se de 81 respondentes (5-ANG, 44-BR, 20-CV, 10-PT e 1-MOÇ e 1-OUT), portanto, como podemos ver, o grau de desconhecimento, percentualmente, é mais patente no Brasil e em Cabo Verde do que em Portugal. A maior parte dos respondentes, no entanto, conhece a palavra e usá-la-ia no género dicionarizado (isto é, no masculino) (73-BR, 8-CV, 1-MOÇ, 99-PT, 2-ST e 7-OUT). 10\% dos informantes usariam a palavra no feminino (25-BR, 3-CV, 5-PT e 1-OUT) e, 3\%, em ambos os géneros (8-BR, 3-CV, 10-PT e 4-OUT). 7\% dos respondentes indicaram ainda uma outra possibilidade (5-BR, 5-PT e 1-OUT), por exemplo, o esgotamento, a síndrome de burnout ou burnout sem "género definido".

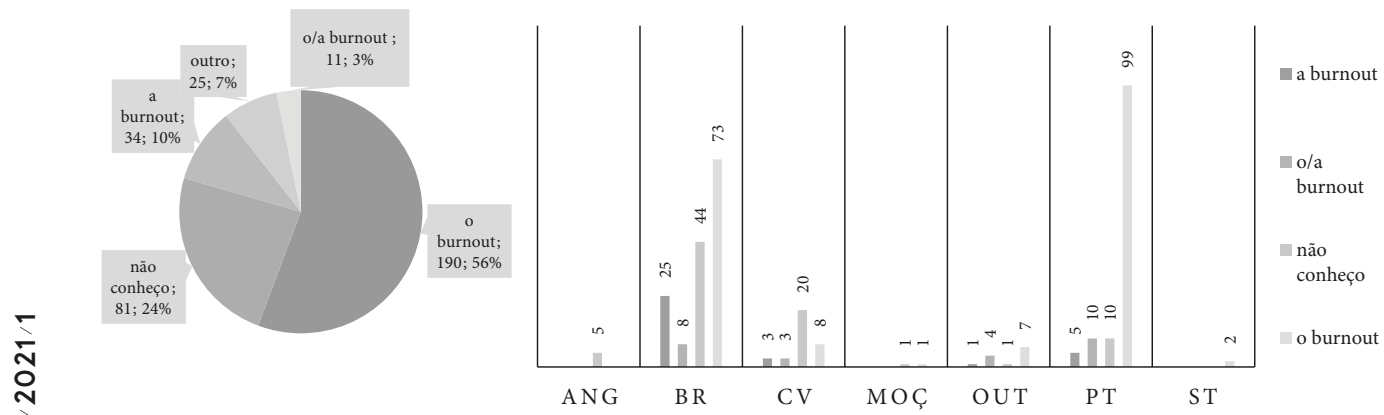

Gráfico 9: Atribuição do género gramatical à palavra BURNOUT

\footnotetext{
6 https://dicionario.priberam.org/burnout

7 https://www.dicio.com.br/burnout/

8 https://ciberduvidas.iscte-iul.pt/artigos/rubricas/idioma/o-lexico-da-covid-19-b/4469
} 
Dos dados foi calculado o coeficiente 46, o qual corresponde ao terceiro grau de oscilação genérica. $13 \%$ dos respondentes $(10 \%+3 \%)$ admitem a atribuição à palavra burnout do género não codificado, isto é, do feminino. Explicamos esta opção pela proximidade à palavra deverbal a queima, eventualmente, num sentido mais figurado ainda, a cremação, incineração, liquidação (de género feminino). Dos fatores sociolinguísticos, não conseguimos identificar nenhum como relevante com a exceção da nacionalidade. Como podemos ver, a oscilação do género evidenciase como maior na categoria dos falantes brasileiros (BR) e cabo-verdianos (CV) do que na dos falantes portugueses (PT).

\section{COVID-19}

A palavra COVID-19 ou covid-19 é um acrónimo do nome inglês COronaVIrus Disease 2019, que designa uma doença infeciosa respiratória, causada pelo coronavírus SARS-CoV-2, identificada pela primeira vez em 2019. Segundo o dicionário PRIBERAM, o nome é de género feminino, mas também pode ser usado no género masculino. É digno de nota que o dicionário HOUAISS trata a entrada COVID-19 como palavra metaftonímica (de acordo com Teixeira 2020), incluindo a seguinte descrição: como substantivo feminino designa "cepa de coronavírus causadora de doença infecciosa cujos primeiros sintomas são febre, cansaço e tosse seca, podendo, em pessoas com outros problemas de saúde, agravar-se e causar dificuldade de respirar"9, e, como substantivo masculino, "infecção por ele causada"10.

No entanto, na lista de Léxico-COVID $19^{11}$ e no dicionário DICIO ${ }^{12}$, conta-se apenas com o seu uso no género feminino. Ao mesmo tempo, no processo de aportuguesamento, o neologismo serve de base de derivação (covídico, covidiano, covidário, anticovid) ou composição (covidiota, covidivórcio, etc).

Os resultados não podem senão confirmar que todos os informantes conhecem esta palavra. Quanto à prioridade do uso do género, como já antecipámos no enquadramento teórico, o coeficiente de oscilação é de 1\%, o que classifica este neologismo como a palavra da máxima oscilação genérica (do quinto grau) não só no âmbito do nosso corpus como também no do léxico português em geral e, possivelmente, também no léxico de outras línguas românicas (sobretudo francesa, italiana e espanhola). 43\% dos respondentes optariam por usar o COVID-19 (1-ANG, 73-BR, 11-CV, 2-MOÇ, 50-PT, 1-ST e 7-OUT), 42\% dos respondentes marcaram a resposta a COVID-19 (4-ANG, 60-BR, 19-CV, 59-PT, 1-ST e 2-OUT) e 15\% dos respondentes usariam a palavra em ambos os géneros (22-BR, 4-CV, 20-PT e 4-OUT) como provam os dados do Gráfico 10.

De entre os fatores sociolinguísticos, podemos destacar o de nacionalidade. Na categoria dos falantes portugueses (PT) e cabo-verdianos (CV) foi registada uma leve preferência pelo género feminino ao contrário da categoria dos falantes brasileiros $(\mathrm{PB})$. O fator de formação também nos traz resultados interessantes: é que a maior parte dos respondentes com a formação secundária

\footnotetext{
9 https://houaiss.uol.com.br

10 https://houaiss.uol.com.br

$11 \mathrm{https} / /$ ciberduvidas.iscte-iul.pt/artigos/rubricas/idioma/o-lexico-da-covid-19-c/4493

12 https://www.dicio.com.br/covid-19/
} 

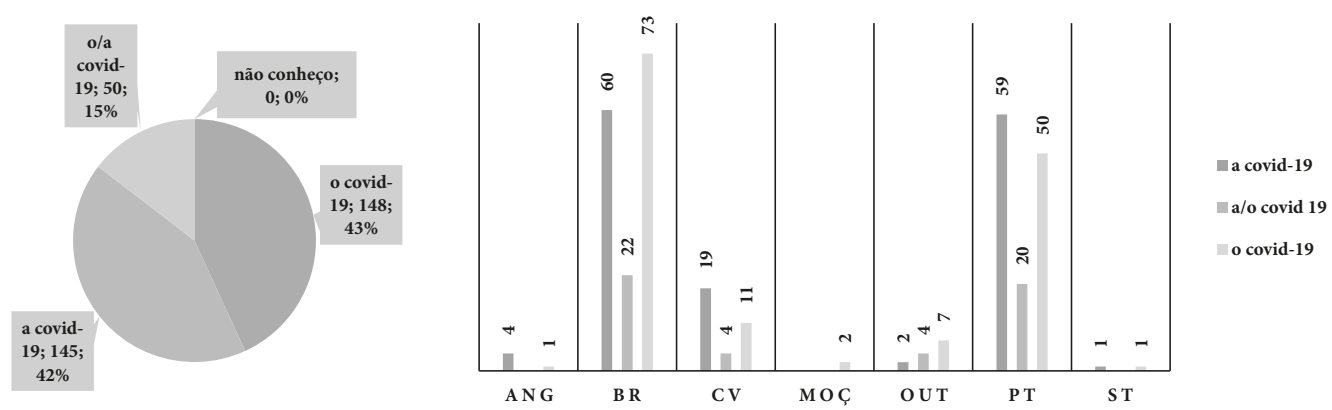

Gráfico 10: Atribuição do género gramatical à palavra COVID-19

(26 do total dos 40 respondentes) prefeririam utilizar a palavra apenas no masculino, enquanto os respondentes com a formação universitária optariam, maioritariamente, por usá-la somenos no feminino (137 do total dos 299 respondentes).

\section{COVID-LONGA}

A expressão covid longa é palavra composta de COVID-19 e do adjetivo longa. Não entrou nos dicionários, ainda que fosse incorporada no Léxico COVID-19 pelo Ciberdúvidas. A expressão designa as consequências da doença de COVID sob a forma de fadiga profunda e outros sintomas “[...] incluindo tosse, falta de ar, dor no corpo e músculos, pressão no peito, palpitações, febre, dor de cabeça, diarreia, entre outros, [...]". ${ }^{13}$

Do ponto de vista morfológico é de esperar que as palavras com a marca de género explícita (longa) sejam utilizadas de acordo com a concordância nominal. A nossa hipótese de COVID-longa ser a expressão usada univocamente no género feminino, no entanto, não se confirmou como podemos observar no seguinte Gráfico 11. Para além de o termo ser desconhecido por 39\% dos respondentes (2-ANG, 60-BR, 7-CV, 2-MOÇ, 60-PT e 3-OUT), 13\% dos respondentes atribuirlhe-iam o género masculino (1-ANG, 17-BR, 8-CV, 14-PT, 1-ST e 2-OUT) e, 6\%, ambos os géneros (7-BR, 4-CV, 6-PT, 2-OUT). Apenas $41 \%$ dos informantes usariam a palavra no feminino (2-ANG, 68-BR, 15-CV, 48-PT, 1-ST e 6-OUT).

Como se pode depreender, o coeficiente de oscilação genérica é de 30 (41\%-11\%), o que corresponde ao quarto grau de oscilação, sendo a palavra no masculino prioritariamente utilizada por $19 \%(6 \%+13 \%)$ dos respondentes. Em nossa opinião, esta oscilação genérica pode ser explicada por dois motivos: a instabilidade genérica do próprio radical COVID e um grau de desconhecimento mais elevado, que, geralmente, pode confirmar a tendência de adotar os estrangeirismos no género mais comum da língua-origem, que é, no caso do inglês, o masculino. Note-se, que, no inquérito apareceram também cinco observações em que os respondentes incluem outras propostas respeitando a concordância nominal (o COVID prolongado, o COVID longo, o longo COVID ou a pandemia prolongada) para além de outras expressões perifrásticas como o vírus que nunca termina. 

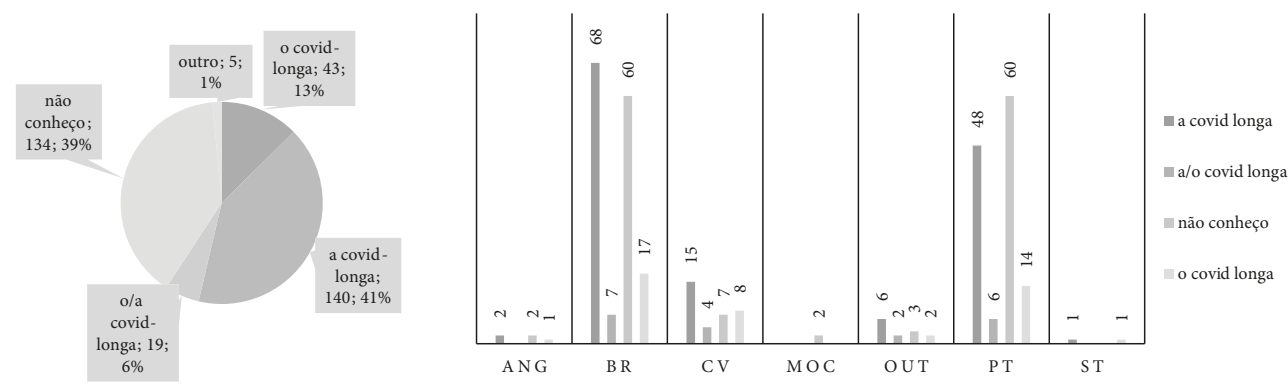

Gráfico 11: Atribuição do género gramatical à palavra COVID-LONGA

Dos fatores que se revelaram como mais marcantes, destaquemos, novamente, o de nacionalidade e o de formação. Há uma leve discrepância no que diz respeito ao conhecimento da palavra, sendo um pouco menos conhecida pelos falantes portugueses (PT) do que brasileiros (BR) ou cabo-verdianos (CV). Também, o critério de formação poderia ser considerado como relevante. Os respondentes com formação secundária usaram os dois nomes em ambos os géneros de um modo equilibrado (11 dos 40 respondentes desta categoria optariam por usar o COVID-longa e, 8 , a COVID-longa - o resto não conhece a palavra ou usa-a em ambos os géneros), enquanto os respondentes com formação universitária preferem, ao contrário, a expressão a COVID-longa (132 respondentes), sendo usada, no género masculino, só por 31 informantes nesta categoria.

\section{COVID-DRIVE}

A palavra covid-drive ou COVID-drive entrou no dicionário PRIBERAM como palavra inglesa, cuja pronúncia, referida pelo mesmo, é |còvidedráive|. A expressão designa "Centro de testes à COVID 19 em que o utente é testado sem ter de sair da viatura"14 e, segundo a mesma fonte, pode aceitar a desinência de plural -s e o género masculino (os COVID-drives). Como no caso anterior, também aqui nos deparamos com uma instabilidade genérica. O coeficiente de oscilação foi de 25 (40\%-15\%), o que corresponde ao quarto grau de oscilação genérica, sendo que, desta vez, a palavra carece de exponente genérico explícito. Os dados são, do ponto de vista da distribuição percentual, muito semelhantes aos anteriores, com a diferença de COVID-drive ser preferencialmente utilizado no masculino. Como o Gráfico 12 prova, $40 \%$ dos respondentes não conhecem a palavra (1-ANG, 75-BR, 8-CV, 49-PT e 3-OUT), 40\% usá-la-iam no género masculino (2-ANG, 57-BR, 14-CV, 2-MOÇ, 51-PT, 2-ST, 8-OUT), 15\%, no género feminino (2-ANG, 18-BR, 9-CV, 23-PT, 1-OUT) e, 4\% dos respondentes usá-la-iam em ambos os géneros (5-BR, 3-CV, 4-PT e 2-OUT). Houve duas propostas pouco relevantes do ponto de vista linguístico (2-PT). 


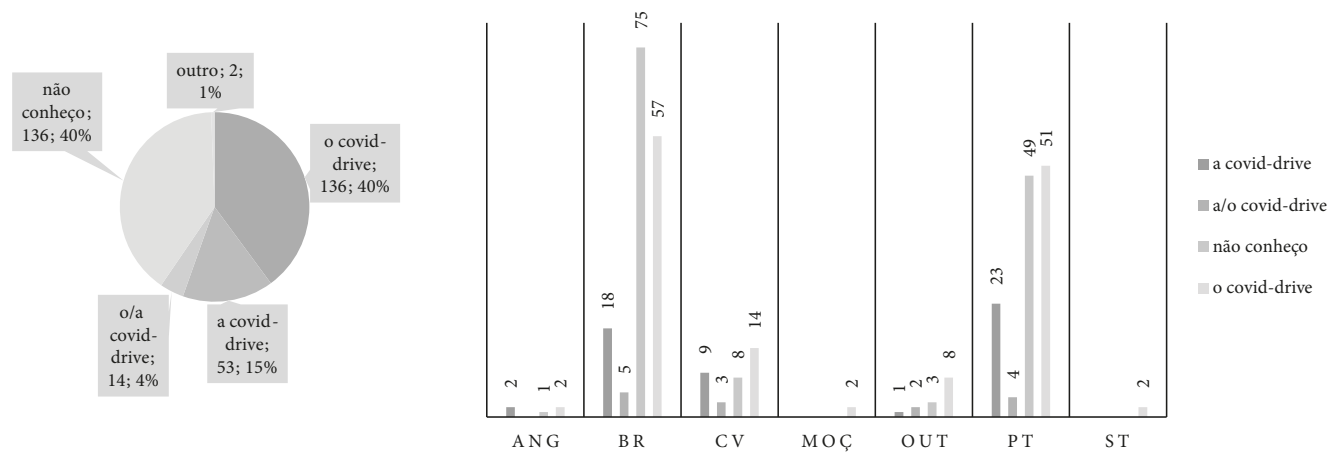

Gráfico 12: Atribuição do género gramatical à palavra COVID-DRIVE

A percentagem de desconhecimento do termo equivale ao anterior e dos dados depreende-se que é menos conhecido no Brasil do que em Portugal ou em Cabo Verde. O género feminino seria atribuído à palavra por $19 \%$ dos respondentes $(4 \%+15 \%)$. Na categoria dos respondentes com formação secundária a oscilação é menor: a palavra foi aceite no feminino por apenas 2 informantes, no masculino, por 20 e, em ambos os géneros, por 8. Na categoria de formação universitária, registou-se uma oscilação muito maior: 51 participantes optariam pelo uso de a COVID-drive, 115 - pelo uso de o COVID-drive, e 12 - por ambos os géneros.

\section{FAKE NEWS}

A palavra fake news é de origem inglesa e ainda que seja um dos termos mais frequentemente usados do século XXI em muitas línguas, refletindo a disseminação de notícias falsas, nem ele, nem o termo equivalente (e.g. notícias falsas) entrou no PRIBERAM. No entanto, a expressão foi integrada nos dicionários DICIO e HOUAISS, e isso como substantivo de género feminino usado no plural. O seu significado é descrito pelas mesmas fontes como "Notícias falsas; quaisquer notícias e informações falsas ou mentirosas que são compartilhadas como se fossem reais e verdadeiras, divulgadas em contextos virtuais, especialmente em redes sociais ou em aplicativos para compartilhamento de mensagens"15 ou, simplesmente, como uma "desinformação"16. De acordo com o Ciberdúvidas, no contexto pandémico, o seu escopo semântico estreitou-se ao de “[...] notícias falsas e nocivas em matéria do COVID-19]"17. Junto com esta palavra, a mesma fonte indica os seus termos equivalentes boato, desinformação, infodemia ou pandemia de desinformação, ilustrando o seu uso, aliás, no género feminino, com vários exemplos de títulos de artigos jornalísticos: Como identificar e combater as "fake news"? ou Relatório alerta para risco de combate às 'fake news' que poder servir para censura nos media. ${ }^{18}$

15 https://www.dicio.com.br/fake-news/

16 https://houaiss.uol.com.br

17 https://ciberduvidas.iscte-iul.pt/artigos/rubricas/idioma/o-lexico-da-covid-19-f/4498]

18 https://ciberduvidas.iscte-iul.pt/artigos/rubricas/idioma/o-lexico-da-covid-19-f/4498] 

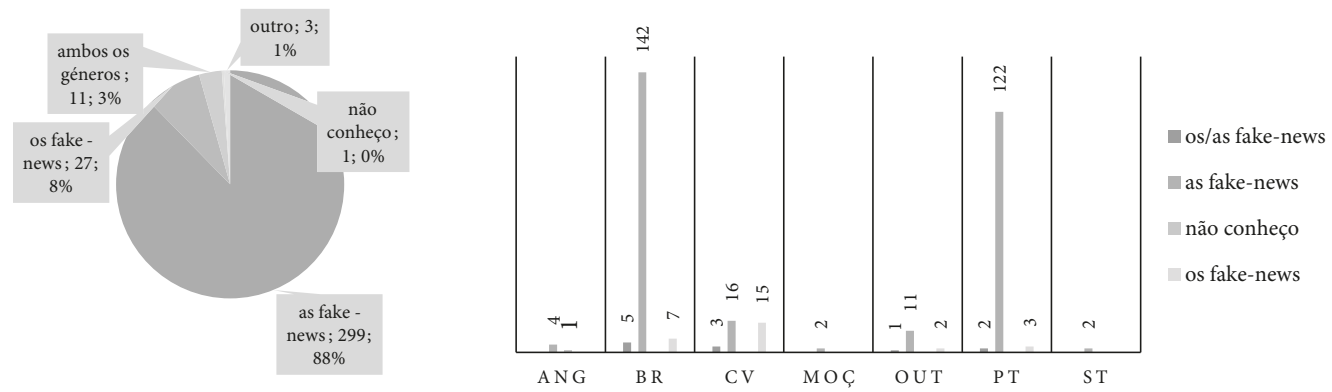

Gráfico 13: Atribuição do género gramatical à palavra FAKE-NEWS

Quanto aos resultados quantitativos, como o Gráfico 13 mostra, a palavra é desconhecida por apenas um participante (1-ANG), sendo maioritariamente utilizada no género feminino, i.e., por 88\% dos respondentes (4-ANG, 142-BR, 16-CV, 2-MOÇ, 122-PT, 2-ST, 11-OUT). O género masculino foi marcado por $8 \%$ (7-BR, 15-CV, 3-PT, 2-OUT) e, ambas as possibilidades foram escolhidas por 3\% dos participantes (5-BR, 3-CV, 2-PT, 1-OUT). 3 informantes (1-ANG, 1-BR, 1-PT) prefeririam utilizar a expressão equivalente notícias falsas.

O coeficiente de oscilação genérica é de 80 ( $88 \%$-8\%), o que corresponde ao segundo grau de oscilação genérica e implica uma fixação genérica mais estável (comparativamente com os outros casos). Quanto à atribuição do género masculino, este seria aceite por, no total, $11 \%(8 \%+3 \%)$ dos respondentes. Destaque-se que a maior oscilação foi verificada na categoria dos falantes caboverdianos $(\mathrm{CV})$ (16 respostas no feminino, mas 15 respostas no masculino). Ao analisar os fatores que influenciam a escolha desta opção, não se chegou a outros resultados relevantes.

\section{HOAX}

É uma palavra inglesa que foi incorporada no dicionário HOUAISS (com base na Wikipedia, mas sem a descrição morfológica) e, para nossa surpresa, também, no MICHAELIS (foi o único neologismo do nosso corpus integrado neste dicionário), que indica que o nome pode ser usado no plural (hoaxes) e no género masculino como, aliás, provam os títulos jornalísticos como: Saiba o que é um hoax ${ }^{19}$. Quanto às suas equivalências semânticas, note-se que para além da sua tradução literal embuste, os nossos informantes sugeriram usar os equivalentes a aldrabice, a farsa, a mentira ou a notícia mentirosa.

Este termo, usado na área da informática, é definido pelas fontes indicadas como: "Notícia ou história falsa recebida pela internet (geralmente em $e$-mail ou em site de relacionamento), a fim de pregar peça nas pessoas ou fazer apelo dramático de cunho sentimental a respeito de algo ou de alguém. Essa mensagem pode também ser utilizada para a obtenção de dados de alguém, que 


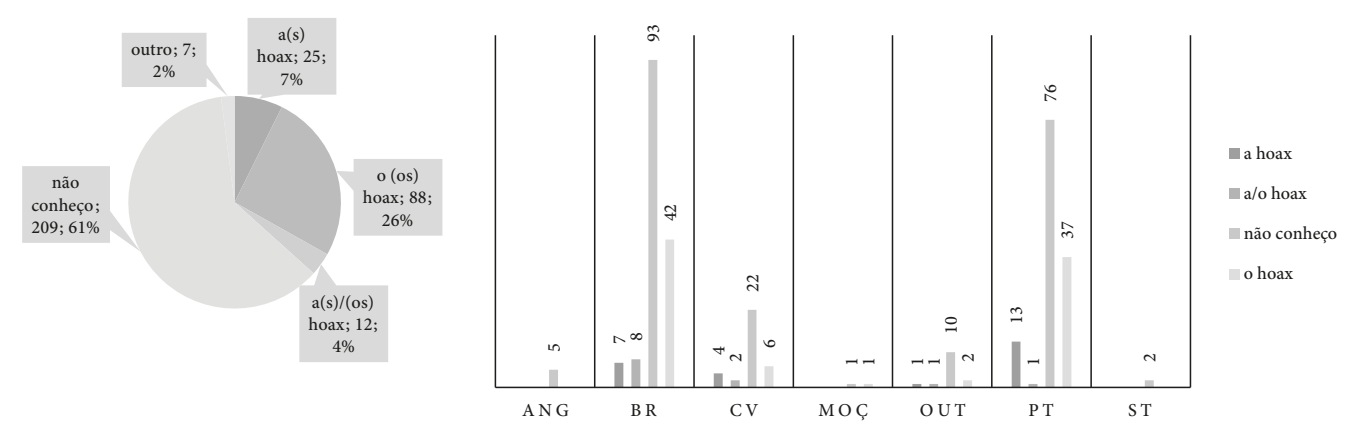

Gráfico 14: Atribuição do género gramatical à palavra HOAX

poderão ser usados posteriormente para fins ilícitos." ${ }^{20}$, ou como "uma tentativa de enganar um grupo de pessoas, fazendo-as acreditar que algo falso é real." ${ }^{21}$.

No contexto pandémico, este tipo de mensagens é usado como ferramenta de manipulação pelos movimentos antimáscaras e antivacinas, que as distribuem entre as gerações mais sensíveis e manipuláveis, isto é, sobretudo, pessoas aposentadas. Estes movimentos advertem de que o coronavírus é um engano e uma fraude, como apura o jornal Reuters no artigo intitulado The coronavirus pandemic is not a hoax or a conspiracy to control the general public. ${ }^{22}$

Como os dados indicam, a palavra não foi adotada pelos países da língua portuguesa, sendo desconhecida por $61 \%$ dos respondentes (5-ANG, 93-BR, 22-CV, 1-MOÇ, 76-PT, 2-ST, 10-OUT). $26 \%$ dos informantes, que conhecem esta expressão, atribuir-lhe-iam o género masculino (42-BR, 6-CV, 1-MOÇ, 37-PT, 2-OUT), 7\%, o género feminino (7-BR, 4-CV, 1-MOÇ, 13-PT, 1-OUT) e, $4 \%$, ambos os géneros (8-BR, 2-CV, 1-PT, 1-OUT), como mostra o Gráfico 14. 7 participantes (5-BR e 2-PT) propõem a substituição pelas expressões como a farsa, o embuste, a aldrabice, a mentira ou a notícia mentirosa.

Quanto ao grau de oscilação, poderíamos prever aqui duas tendências opostas: ou o grau de desconhecimento (61\%) mais elevado levará ao seu uso maioritário no masculino ou a diversidade genérica das suas equivalências (compare-se: o embuste e a mentira, etc.) levará a uma maior oscilação. Curiosamente, ambas as hipóteses se verificaram. Apesar das suas possíveis associações com os termos genericamente diversos, prevalece, o género masculino. Quanto ao seu uso no género feminino, por este optaram, no total, $11 \%$ dos respondentes $(7 \%+4 \%)$. O coeficiente de oscilação genérica é 19 (26\%-7\%), o que corresponde ao máximo, o quinto, grau. De ressaltar que, na categoria dos participantes de (CV), a oscilação revelou-se maior que na categoria dos falantes portugueses (PT) e brasileiros (BR).

\footnotetext{
20 https://michaelis.uol.com.br/moderno-portugues/busca/portugues-brasileiro/hoax/

21 https://houaiss.uol.com.br

22 https://www.reuters.com/article/uk-factcheck-hoax-idUSKBN25G2KM
} 


\section{LOCKDOWN}

A palavra lockdown é de origem inglesa e foi integrada como um nome de género masculino nos dicionários HOUAISS e DICIO. O seu sinónimo mais frequentemente mencionado é confinamento, e é definida como "ação de isolar pessoas, confinando-as por certo tempo (em casa, num navio num hospital, etc.), por medida de segurança (durante pandemias, p. ex.)"23 ou como "bloqueio que, imposto pelo Estado ou por uma ação judicial, restringe a circulação de pessoas em áreas e vias públicas, incluindo fechamento de fronteiras e que geralmente ocorre em situações de pandemia com o intuito de evitar a disseminação do vírus" ${ }^{24}$. É digno de nota que, segundo várias fontes, o primeiro acontecimento em cujo contexto a palavra foi usada foram os ataques de 11 de setembro quando foi iniciado um lockdown de três dias no espaço aéreo civil americano ${ }^{25}$. No contexto da pandemia, a palavra tem sido usada no sentido de "[...] a medida mais radical imposta por governos para que haja distanciamento social - uma espécie de bloqueio total em que as pessoas devem, de modo geral, ficar em casa" ${ }^{\text {"26. }}$. O seu uso no género masculino pode ser documentado pelos títulos jornalísticos como: Entenda o que é o lockdown decretado por estados e municípios ou Reino Unido retoma lockdown mais rigoroso por seis semanas. ${ }^{27}$

Como mostra o Gráfico 15, lockdown é desconhecido por apenas 5\% dos informantes (1-ANG, 7-CV, 8-PT). 87\% respondentes usariam a palavra no género masculino (4-ANG, 150-BR, 19-CV, 2-MOÇ, 108-PT, 2-ST e 12-OUT). 4\% dos respondentes optariam pelo género feminino (2-BR, 6-CV, 5-PT, 1-OUT) e, 2\% dos respondentes, por ambas as possibilidades (1-BR, 2-CV, 5-PT, 1-OUT). 7 respondentes (2-BR, 4-PT, 1-OUT) sugeriram usar as seguintes expressões equivalentes: fechamento, encerramento e confinamento.

O coeficiente de oscilação genérica é de 83 (87\%-4\%), o que corresponde ao primeiro grau de oscilação, que implica a maior estabilidade possível. Com efeito, o uso da expressão no feminino revela-se esporádico, sendo admitido por apenas $6 \%$ dos informantes $(2 \%+4 \%)$, que a associam,
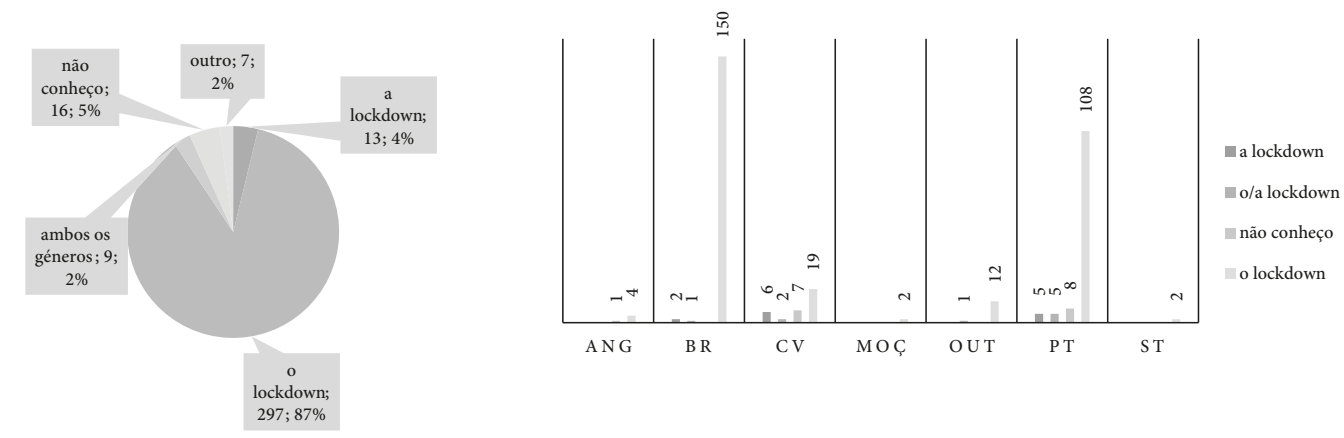

Gráfico 15: Atribuição do género gramatical à palavra LOCKDOWN 
provavelmente, ao nome casa, que faz parte implícita da sua definição. A opção por este género ou por ambos os géneros, decorre, praticamente, na mesma medida em todas as categorias observadas. Quanto ao fator geográfico, podemos, novamente, reparar num uso mais oscilante na categoria dos participantes de Cabo Verde (CV) (6 informantes aceitariam a palavra somenos no feminino, e 19, apenas no masculino).

\section{REMDESIVIR/RENDESIVIR}

Remdesivir (PE) ou rendesivir $(\mathrm{PB})$ é um medicamento antiviral desenvolvido pela companhia biofarmacêutica Gilead Sciences, originalmente para o tratamento do ébola e do vírus de Marburg. ${ }^{28}$ No contexto pandémico, foi aprovado ou autorizado o seu uso de forma condicional para o tratamento da COVID-19 nos pacientes internados, em aproximadamente 50 países $^{29}$ (Argentina, Estados Unidos, Índia, Israel, Japão, Rússia, Coreia do Sul e Canadá, União Europeia), mas ainda não foi adotado no Brasil. E, como tal, pressupõe-se não ser conhecido, sobretudo, por parte dos falantes brasileiros. A palavra, nos meios-de comunicação, é usada no género masculino, como prova o título do artigo jornalístico: Agência Brasil explica o que é o rendesivir ${ }^{30}$ ou Remdesivir, remédio aprovado para tratar COVID, ainda não foi adotado no Brasil ${ }^{31}$.

Como os dados do Gráfico 16 mostram, é desconhecida por 43\% dos respondentes (3-ANG, 71-BR, 18-CV, 1-MOÇ, 45-PT, 1-ST, 4-OUT). 47\% optariam por usá-la no masculino (2-ANG, 75-BR, 6-CV, 1-MOÇ, 71-PT, 1-ST, 7-OUT), 5\% dos respondentes, no feminino (2-BR, 4-CV, 10-PT) e 5\%, em ambos os géneros (7-BR, 6-CV, 2-PT, 2-OUT). Um respondente (1-PT) indicou a prioridade de usar a expressão o medicamento remdesivir.
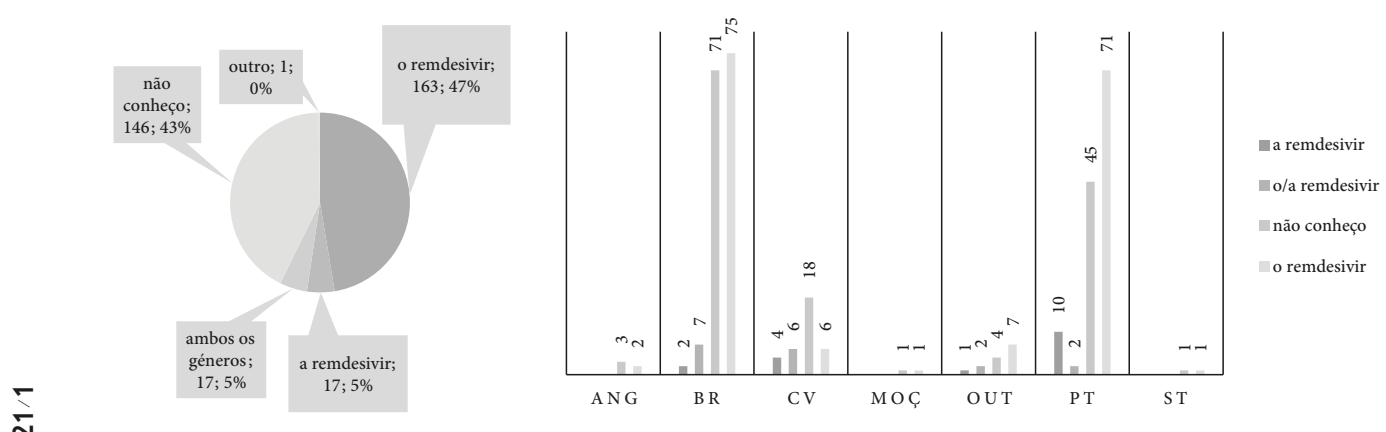

Gráfico 16: Atribuição do género gramatical à palavra REMDESIVIR

28 https:/epoca.globo.com/brasil/remdesivir-que-o-antiviral-contra-covid-19-aprovado-pela-anvisa-24922199

29 https://www.gilead.com/news-and-press/press-room/press-releases/2020/10/us-food-and-drug-administrationapproves-gileads-antiviral-veklury-remdesivir-for-treatment-of-covid19

30 https://agenciabrasil.ebc.com.br/saude/noticia/2021-03/agencia-brasil-explica-o-que-e-o-rendesivir-aprovadopara-tratamento

31 https://saude.ig.com.br/coronavirus/2021-04-13/remdesivir--remedio-aprovado-para-tratar-covid--ainda-naofoi-adotado-no-brasil.html 
Como era de esperar, a palavra é desconhecida, sobretudo, pelos informantes brasileiros (BR) e cabo-verdianos (CV). O coeficiente de oscilação genérica é de 42 (47\%-5\%), o que corresponde ao terceiro grau de oscilação. Como decorre dos resultados, a expressão no feminino seria aceite por $10 \%$ dos respondentes (isto é $5 \%+5 \%$ ). Trata-se de informantes portugueses, brasileiros e cabo-verdianos que, provavelmente, associam a expressão à palavra medicina ou substância. Em Cabo-Verde, novamente, testemunhamos uma maior oscilação genérica. Quanto aos outros fatores, nenhuns, à exceção do diatópico, se mostraram decisivos.

\section{WEBINAR}

O termo webinar é uma palavra inglesa derivada do radical web (rede mundial de computadores). Foi incorporado nos dicionários PRIBERAM e HOUAISS (neste último com base na Wikipedia). O PRIBERAM menciona a sua pronúncia |uébinàr|, atribui-lhe o género masculino e indica a possibilidade de formar o plural (plural: webinars). HOUAISS só se refere às ditas categorias gramaticais nas expressões webinário ou webnário, deixando a questão da caracterização morfológica de webinar não especificada. A palavra é usada na área da Informática, mas importa salientar que as fontes não condizem no que diz respeito à componente de interação na sua descrição semântica. PRIBERAM define-a como sinónimo de webinário, i.e., como "Seminário ou apresentação com fins didácticos realizado pela Internet para um grupo de pessoas, geralmente com interacção" ${ }^{2}$. No entanto, HOUAISS carateriza-o como uma atividade unidirecional, isto é, como "[...] um tipo de webconferência no qual a comunicação é de uma via apenas, ou seja, somente uma pessoa se expressa e as outras assistem"33, integrando as expressões webnário/webinário como entradas separadas com o significado, mais genérico, de "seminário efetuado pela Internet." ${ }^{34}$ De acordo com o Ciberdúvidas, trata-se de estrangeirismo, que, no contexto da crise sanitária, tem sido “[...] um dos formatos adotados para promover conferências e palestras no âmbito da educação digital." 35

Os dados do inquérito mostraram que o termo é desconhecido por $13 \%$ dos respondentes (2-ANG, 26-BR, 7-CV, 8-PT, 1-ST e 1-OUT), sendo maioritariamente usado no género masculino, marcado por 62\% dos respondentes (2-ANG, 91-BR, 17-CV, 1-MOÇ, 88-PT, 1-ST e 10-OUT). No entanto, $18 \%$ dos respondentes usariam a palavra no género feminino (26-BR, 7-CV, 1-MOÇ, 24-PT e 2-OUT), 6\% em ambos os géneros (1-ANG, 8-BR, 3-CV, 8-PT e 1-OUT) e 5 informantes sugeriram uma outra possibilidade (4-BR, 1-PT) como, por exemplo, seminário online, conferência à distância. A proposta mais surpreendente, no entanto, foi a de uma falante brasileira, com ensino universitário, que utiliza a expressão como verbo (p. ex. na frase por ela indicada: Vou webinar), não aceitando a sua interpretação nominal. Veja-se os dados do Gráfico 17.

O coeficiente de oscilação é de 43 (61\%-18\%), o que corresponde ao terceiro grau. Provavelmente, tal é causado pela associação da expressão, também, ao termo equivalente página web. No feminino, seria aceite por $24 \%$ dos respondentes $(6 \%+18 \%)$. A oscilação revela-se maior na

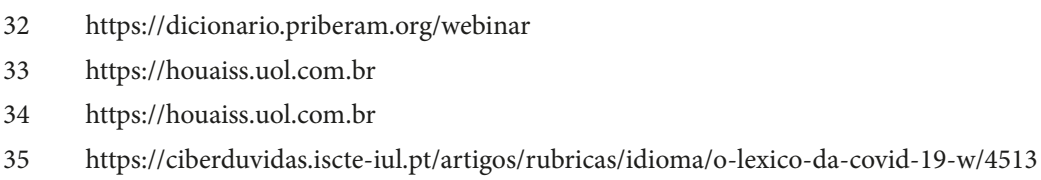



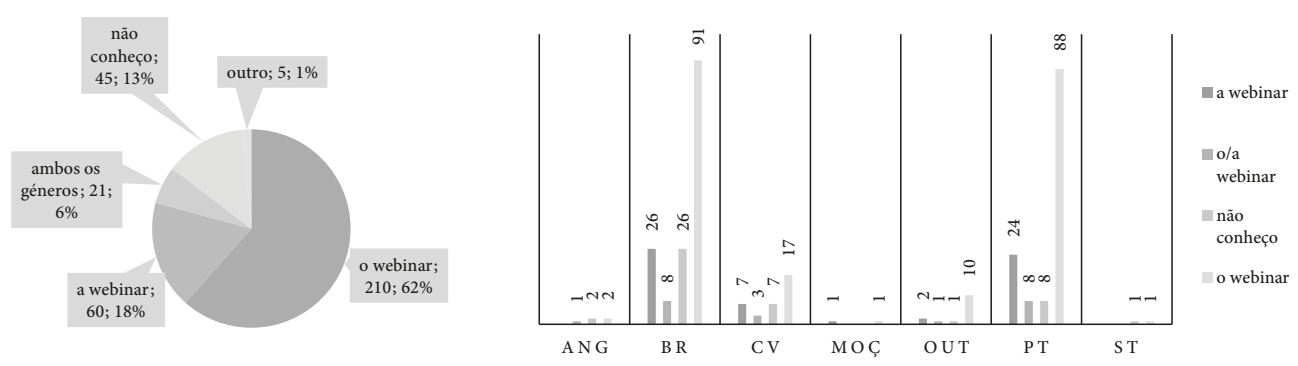

Gráfico 17: Atribuição do género gramatical à palavra WEBINAR

categoria dos falantes cabo-verdianos (CV) (7 respostas no feminino e, 17, no masculino) e, principalmente, na dos informantes com formação secundária (10 respostas no feminino, 12 , no masculino e, 4, em ambos os géneros). Na categoria da formação universitária, a oscilação foi menor: a maior parte usa a palavra no masculino (197 informantes), sendo admitido o feminino por 50 respondentes e, ambos os géneros, marcados por 17 informantes.

\section{ZOONOSE}

A palavra zoonose, de origem inglesa, foi incorporada como palavra de género feminino nos dicionários DICIO ${ }^{36}$, HOUAISS $^{37}$, e PRIBERAM. Esta última fonte inclui, na sua descrição, igualmente, uma anotação relativa à pronúncia, indicando |ó| semiaberto, e à possibilidade de formar o plural, dando como exemplo a frase $A$ brucelose e a psitacose são zoonoses. ${ }^{38} \mathrm{~A}$ expressão é usada na área da veterinária com o significado de "Nome genérico dado a várias doenças infecciosas dos animais, geralmente transmissíveis ao ser humano". O Ciberdúvidas, no contexto pandémico, define o seu significado como "doença infecciosa, proveniente de um animal vertebrado e transmissível, em condições naturais, ao homem"39, de que nasceu o coronavírus, ilustrando o seu uso pelo título do artigo jornalístico: Coronavírus: como a pandemia nasceu de uma zoonose. ${ }^{40}$

Sendo um conceito especializado, usado na área da veterinária, não é surpreendente o desconhecimento desta palavra por 38\% dos respondentes (4-ANG, 21-BR, 18-CV, 78-PT e 8-OUT). Pelo género feminino optariam $49 \%$ dos respondentes (1-ANG, 122-BR, 6-CV, 31-PT, 2-ST e 4-OUT), e pelo género masculino, 10\% dos informantes (7-BR, 8-CV, 16-PT, 2-MOÇ e 1-OUT). $3 \%$ dos respondentes usariam a palavra em ambos os géneros (4-BR, 2-CV, 4-PT, 1-OUT). 1 respondente (1-BR) indicou, no comentário, que zoonose não era neologismo. Os dados podem ser consultados no seguinte Gráfico 18:

\footnotetext{
36 https://www.dicio.com.br/zoonose/

37 https://houaiss.uol.com.br

38 https://dicionario.priberam.org/zoonose

$39 \mathrm{https} / /$ ciberduvidas.iscte-iul.pt/artigos/rubricas/idioma/o-lexico-da-covid-19-z/4515

40 https://ciberduvidas.iscte-iul.pt/artigos/rubricas/idioma/o-lexico-da-covid-19-z/4515
} 

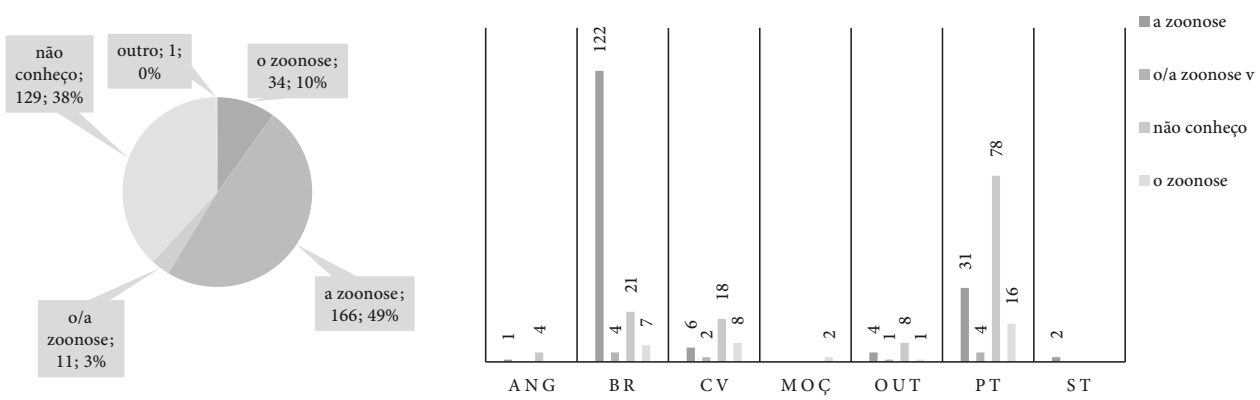

Gráfico 18: Atribuição do género gramatical à palavra ZOONOSE

Como podemos observar, o maior grau de desconhecimento desta expressão caracteriza a categoria dos informantes portugueses e cabo-verdianos. O coeficiente de oscilação é de 39 (49\%-10\%), o que corresponde ao segundo grau de oscilação. O género masculino é aceitável para $13 \%(10 \%+3 \%)$, provavelmente pela associação à palavra nariz, de género masculino. Enquanto na categoria dos respondentes brasileiros (BR), o género de zoonose é mais estabilizado, na dos falantes portugueses (PT) e cabo-verdianos (CV), podemos observar um maior grau de oscilação. Em PT, por exemplo, 31 falantes usariam a palavra no feminino, mas, 16, no masculino e, 4, em ambos os géneros. Já agora, em CV, há indícios da predominância do género masculino, provavelmente dada por um maior grau de desconhecimento (obtivemos 8 respostas no masculino, 6, no feminino e, 2, em ambos os géneros).

\section{Conclusão}

Através da comparação quantitativa, ordenámos as palavras analisadas de acordo com a percentagem de desconhecimento do modo seguinte: hoax (61\%), o remdesivir (43\%), o COVID-drive (40\%), a COVID-longa (39\%), a zoonose (38\%), o burnout (24\%), o webinar (13\%), o lockdown (5\%) sendo a COVID-19 e as fake-news conhecidas por todos os informantes, como demonstra a Tabela 2.

Dos dados nela apresentados torna-se evidente que o dicionário mais dinâmico, que mais rapidamente refletiu a situação pandémica, é o HOUAISS. Entre os menos dinâmicos, encontram-se o AULETE e o MICHAELIS.

Ao mesmo tempo, no que diz respeito à incorporação dos covid-xenismos. deparámo-nos com curiosidades, dignas de nota.

Em primeiro lugar, as palavras a COVID-19 e as fake-news, conhecidas por todos os falantes, não são introduzidas em todos os dicionários. Surpreendentemente, o último termo não foi incorporado, não só nos dicionários MICHAELIS e AULETE, que se mostraram mais imunes aos xenismos em geral (inclusive ao próprio COVID-19), como nem sequer no PRIBERAM. O mesmo pôde observar-se noutros neologismos com um maior grau de conhecimento ainda (p. ex.: lockdown).

Outras lexias, mais desconhecidas (o COVID-drive, a zoonose), por outro lado, foram incorporadas. A incorporação de covid-drive implica não só a desproporção entre o grau de desconheci- 
mento e a dicionarização como também o facto de não ser respeitada a sequência cronológica da importação dos estrangeirismos para o português (fake-news e hoax, expressões não dicionarizadas, certamente, eram usadas ainda antes da pandemia e antes da dicionarização de covid-drive).

A maior surpresa foi a inclusão de hoax, palavra menos conhecida pelos respondentes, no dicionário menos dinâmico, o MICHAELIS, enquanto noutros dicionários geralmente mais dinâmicos não foi incorporada.

Estes resultados levam-nos a considerar o critério lexicográfico como importante, mas não como o principal na determinação dos neologismos. Como mostra a seguinte tabela, a dicionarização, realmente, nem sempre reflete o grau de (des) conhecimento dos neologismos por parte dos falantes (à exceção do HOUAISS).

Dos dados ainda podemos deduzir que todos os neologismos por nós estudados encontraram pelo menos uma "residência" fixa, ficando apenas rem(n)desivir sans domicile fixe (SHF).

\begin{tabular}{|c|l|c|c|c|c|c|c|}
\hline$\downarrow$ & \multicolumn{1}{|c|}{ Neologismo } & \multicolumn{2}{c|}{$\begin{array}{c}\text { Percentagem de } \\
\text { desconhecimento }\end{array}$} & \multicolumn{3}{c|}{ Dicionarização (+ integrado, não integrado) } \\
\cline { 4 - 7 } & & & HOUAISS & PRIBERAM & DICIO & MICHAELIS & AULETE \\
\hline 1. & os hoax & $61 \% \downarrow$ & + & - & - & + & - \\
\hline 2. & o remdesivir & $43 \% \downarrow$ & - & - & - & - & - \\
\hline 3. & o COVID-drive & $40 \% \downarrow$ & - & + & - & - & - \\
\hline 4. & a COVID-longa & $39 \% \downarrow$ & - & - & - & - & - \\
\hline 5. & a zoonose & $38 \% \downarrow$ & + & + & + & + & - \\
\hline 6. & o burnout & $24 \% \downarrow$ & + & + & + & - & - \\
\hline 7. & o webinar & $13 \% \downarrow$ & + & + & - & - & - \\
\hline 8. & o lockdown & $5 \% \downarrow$ & + & - & + & - & - \\
\hline 9. & a COVID-19 & $0 \% \downarrow$ & + & + & + & - & - \\
\hline 10 & as fake-news & $0 \% \downarrow$ & + & - & + & - & - \\
\hline TOTAL DAS PALAVRAS INTEGRADAS & 7 & 5 & 5 & 2 & 0 \\
\hline
\end{tabular}

Tabela 2: Desconhecimento percentual dos neologismos e incorporação em nos dicionários

Quanto à instabilidade de género, em cada um dos neologismos calculámos o "coeficiente de oscilação genérica", que mostra que quanto menor é a diferença entre os valores percentuais do feminino e do masculino, tanto mais instável se revela a fixação genérica pelos falantes nativos. Dividimos os coeficientes em cinco graus, em que o grau 5 implica a maior, e, o grau 1, a menor oscilação.

No entanto, podemos verificar que o grau de oscilação não corresponde à percentagem da aceitação de ambos os géneros, que orbita, praticamente, em todos os casos, em torno de 2-6\% (à exceção de em o COVID-19) como mostra a Tabela 3. Para além disso, como ao longo do trabalho apontámos, o grau de oscilação pode divergir segundo o fator diatópico. Particularmente, em Cabo Verde, observa-se uma oscilação maior do que em Portugal e no Brasil. 


\begin{tabular}{|c|l|c|c|c|}
\hline$\downarrow$ & \multicolumn{1}{|c|}{ Neologismo } & $\begin{array}{c}\text { Índice de oscilação genérica } \\
(\%)\end{array}$ & $\begin{array}{c}\text { Grau de oscilação } \\
\text { (na escala de 1-5) }\end{array}$ & $\begin{array}{c}\text { Aceitação de ambos os } \\
\text { géneros }\end{array}$ \\
\hline 1. & a COVID-19 & $1 \downarrow$ & 5 & $15 \%$ \\
\hline 2. & os hoax & $19 \downarrow$ & 5 & $4 \%$ \\
\hline 3. & o COVID-drive & $25 \downarrow$ & 4 & $4 \%$ \\
\hline 4. & a COVID-longa & $28 \downarrow$ & 4 & $6 \%$ \\
\hline 5. & a zoonose & $39 \downarrow$ & 4 & $5 \%$ \\
\hline 6. & o remdesivir & $42 \downarrow$ & 3 & $6 \%$ \\
\hline 7. & o webinar & $44 \downarrow$ & 3 & $3 \%$ \\
\hline 8. & o burnout & $46 \downarrow$ & 2 & $3 \%$ \\
\hline 9. & as fake-news & $80 \downarrow$ & 1 & $2 \%$ \\
\hline 10. & o lockdown & $83 \downarrow$ & 3 & $5 \%$ \\
\hline
\end{tabular}

Tabela 3: Índice de oscilação genérica e aceitação de ambos os géneros

Conclua-se que a fixação do género gramatical por qualquer ferramenta linguística vai sempre, em menor ou maior grau, enfrentar o problema de confronto com o uso real na linguagem corrente, já que se vê sujeita a processos cognitivos que nunca serão coincidentes em todos os falantes. Estamos convencidos de que a inclusão de informações mais detalhadas relativas à oscilação do género e ao uso, mais ou menos periférico em cada uma das variedades, ajudariam os utentes (falantes quer nativos quer não nativos) da língua portuguesa a orientarem-se melhor no seu uso. Por isso, opinamos que o método e os índices propostos poderão contribuir para uma dicionarização mais efetiva dos neologismos na lexicografia portuguesa.

\section{Referências bibliográficas}

Alves, I. M. (1994). A integração dos neologismos por empréstimo ao léxico português. Alfa, 119-126. . (2002). Neologismo - criação lexical. 2 ed. São Paulo: Ática.

Cabré Castellví, M. T. (2006). La clasificación de neologismos: una tarea compleja. Alfa, 50, 2, 229-250.

Biderman, M. T. C. (2001). Fundamentos da Lexicologia. In Teoria linguística: teoria lexical e computacional (pp. 99-155). São Paulo: Martins Fones.

Boulanger, J. C. de (1979). Néologie et terminologie. Néologie en Marche, 4, 5-128.

Carvalho, D. da S. (2021). A Domesticação da Gramática de Gênero. São Paulo: Pontes Editores.

Carvalho, N. M. (1987). O que é neologismo. 2 ed. São Paulo: Brasiliense.

Correia, M.; \& Almeida, G. M. de B. A. (2012). Neologia em português. São Paulo: Parábola.

Eckert, K. (2019). Observatório de neologismos da língua portuguesa: da sala de aula para a pesquisa. Linguatec, 3, 1, 1-19. 
Ferraz, A. P. (2008). Neologismos semânticos na publicidade impressa: uma abordagem cognitivista. In A. N. Isquerdo, \& M. J. B. Finatto (Orgs.). As ciências do léxico: lexicologia, lexicografia, terminologia. vol. IV. Campo Grande: UFMS/UFRGS.

Gouveia, M. C. de F. e (2003). O género dos estrangeirismos usados na língua portuguesa. In Actas do VIII Encontro Nacional da Associação Portuguesa de Linguística (pp. 411-419). Lisboa: APL.

Haugen, E. (1950). The analysis of linguistic borrowing. Language, 26, 210-231.

Jabłonka, E. (2016). Introdução das unidades lexicais estrangeiras no português atual. Estudo baseado em blogues femininos portugueses e brasileiros. Lublin: Wydawnictwo UMCS.

Polická, A. (2018). Lexikální inovace Dynamika šírení identitárních neologismů. Tese de habilitação. Universidade de Masaryk, Brno (355 p).

Rio-Torto, G. (2020). Renovação do Léxico no Português brasileiro e europeu. Da neologia técnico-científica à neologia expressiva, humorística, lúdica. Labor Histórico, 6, 3, 196-223.

Sablayrolles, J.-F. (2019): Comprendre la néologie. Conceptions, analyses, emplois. Limoges: Lambert Lucas.

Teixeira, J. (2020). Metáforas da Vida Co(v)idiana. Estudos Linguísticos e Literários, 69, número especial, 21-51.

Tournier, N.; \& Tournier, J. (2009). Dictionnaire de lexicologie française. Paris: Ellipses.

\section{Recursos online}

(todos os recursos online foram consultados nos meses de março e abril de 2021)

\section{Dicionários e enciclopédias}

https://aulete.com.br

https://dicionario.PRIBERAM.org

https://dicio.com.br

https://michaelis.uol.com.br

https://houaiss.uol.com.br

https://pt.wikipedia.org/wiki/

\section{Recursos on-line linguísticos}

https://ciberduvidas.iscte-iul.pt/lexico-COVID-19

https://www.normaculta.com.br/neologismo/

\section{Inquérito}

https://www.survio.com/survey/d/D8Q4A4A2J3K4T2N6S

\section{Textos jornalísticos}

https://www.reuters.com/article/uk-factcheck-hoax-idUSKBN25G2KM

https://memoria.ebc.com.br/tecnologia/2012/09/saiba-o-que-e-um-hoax

https:/g1.globo.com/bemestar/coronavirus/noticia/2020/05/06/entenda-o-que-e-lockdown.ghtml 
https://epoca.globo.com/brasil/remdesivir-que-o-antiviral-contra-COVID-19-aprovado-pela-anvisa-24922199

https://www.gilead.com/news-and-press/press-room/press-releases/2020/10/us-food-and-drug-administration-approves-gileads-antiviral-veklury-remdesivir-for-treatment-of-COVID19

https://agenciabrasil.ebc.com.br/saude/noticia/2021-03/agencia-brasil-explica-o-que-e-o-rendesivir-aprovado-para-tratamento

https://saude.ig.com.br/coronavirus/2021-04-13/remdesivir--remedio-aprovado-para-tratar-COVID--ainda-nao-foi-adotado-no-brasil.html 